\title{
The use of a high-fidelity simulation manikin in teaching clinical skills to fourth year undergraduate pharmacy students
}

\author{
NICHOLAS HADDINGTON ${ }^{1,2 *}$, LYN HANNING ${ }^{1,3}$, MARJORIE WEISS $^{1}$, DENISE TAYLOR ${ }^{1}$ \\ ${ }^{I}$ Department of Pharmacy and Pharmacology, University of Bath, Claverton Down, Bath, BA2 7AY, U.K. \\ ${ }^{2}$ Pharmacy Department, Great Western Hospitals Foundation Trust, Marlborough Road, Swindon, SN3 6BB, U.K. \\ ${ }^{3}$ South West Medicines Information and Training, Bristol Royal Infirmary, Bristol, BS2 8HW, U.K.
}

\begin{abstract}
Background: A relatively new development in simulation-based teaching in healthcare education is the use of simulation manikins. While these have been used to teach clinical skills in various health disciplines, little has been reported on their use in UK undergraduate pharmacy programmes.
\end{abstract}

Aims: To investigate the use of a simulation manikin to teach clinical skills to undergraduate pharmacy students.

Method: A fourth year unit was developed to teach clinical skills to undergraduate pharmacists, including communication, consultation skills, clinical decision making and physical examination. A pre- and post-unit questionnaire was used to gather data relating to student confidence, self rated competence and student experience.

Results: Student confidence and self-rated competence in key clinical skills increased significantly. High levels of acceptability for this teaching method were reported.

Conclusion: This method of teaching clinical skills is effective and highly acceptable to undergraduate pharmacy students. Further research is necessary to compare this to other methods.

Keywords: Simulation, SimMan ${ }^{\circledR}$, clinical skills, undergraduate, pharmacy

\section{Introduction}

\section{Simulation-based teaching in healthcare}

The use of simulation-based teaching within health-discipline programmes is well established (Issenburg \& Scalese, 2008; Rosen, 2008). It has been used to teach a range of clinical skills, including physical examination, therapeutic interventions, structured communication, clinical decision making and team working. The use of simulation-based teaching in practice has been described in detail and reviewed by a number of authors (Issenburg et al., 1999; Issenburg et al., 2005; Issenburg \& Scalese, 2008). Simulation-based teaching methods include real-life (physical) situations involving actors, standardised patients and physical simulation tools. These may also be integrated into assessments such as 'OSCEs' (observed structured clinical examinations).

Numerous physical simulators have been developed to teach specific physical skills. Examples include pelvic floor examination simulators, resuscitation aids for teaching lifesupport (CPR) skills, and physiologically realistic arms for cannulation and phlebotomy techniques (Pugh \& Youngblood 2002). These 'sections' of physical anatomy have been described as 'part-task trainers' (Issenburg \& Scalese, 2008). More recently, purely electronic (virtual) simulation environments have been developed, including bespoke programmes, such as those developed and described by Chapman and Bracegirdle (2010) to teach clinical skills to pharmacists. Others have used pre-existing simulation platforms such as Second Life to develop skills teaching (Lee \& Berge, 2011).

Physical examination skills can be taught by a number of methods, traditionally including interaction or role-play with peers, actors or real patients. While these are often suitable for examining healthy physiology, a problem arises when a disease state is required for students to examine (Hatala et al., 2008). Another method available for familiarisation with indicative sounds is to use audio recordings, but this takes the sign out of context, and removes the practice of diagnostic skill (Mangione \& Nieman, 1997).

The use of standardised patients with disease states is the traditional solution for medical students. While being of absolute fidelity, the practicalities of finding and providing access to such patients for students to examine can be complex and intensive student exposure can be tiring and distressing for patients. Additionally, there are perceived

*Correspondence: Mr. Nicholas Haddington, Department of Pharmacy and Pharmacology, University of Bath, Claverton Down, Bath, BA2 7AY, U.K. Tel: +44 (0)1225383290 (Monday and Thursday); +44 (0) 1793605033 (Tuesday, Wednesday and

Friday).Email:nicholas.haddington@gwh.nhs.uk; pr9njh@bath.ac.uk 
disadvantages (with real patients) in the learner (and patient) safety of the situation, and the opportunity to experiment with and to refine examination skills (Pugh \& Youngblood, 2002; Bokken et al., 2009).

\section{The Use of Human Patient Simulators (HPS)}

A simulation manikin can provide a solution to some of these problems. Simulation manikins, also known as 'Human patient simulators' (HPSs) or 'Computer-Enhanced Manikin Simulators' (CEMs), such as the Laerdal's SimMan ${ }^{\circledR}$ range and the Medical Education Technologies, Inc. (METI) range of simulators, blend both physical and virtual features in order to create a high-fidelity patient simulator. This can contribute to a highly immersive healthcare simulation. HPSs have a number of beneficial features that can aid learning. They can be programmed to simulate a number of different pathophysiologies in context and situ, on demand, in a reproducible way. The issues related to the use of real patients are minimised and a safer learning environment achieved.

The major perceived drawback of simulation manikins is the limitation of fidelity that is still inherent. Despite realistic physical features, manikins have rubbery skin and are cold to the touch; their faces are unresponsive, unemotional and do not move realistically when the manikins speak. These are currently unavoidable artefacts of a simulation manikin, and they may limit the achievable realism, and detract from the learning experience.

In terms of physiological response to administered drugs, a simulation manikin represents a sophisticated way of reproducing physiological responses to medicines in a realistic physical context. Alternative methods of simulating physiological responses to drug administration include administration to an animal, which may not simulate human responses accurately and may be perceived as ethically unacceptable for teaching purposes, or use of computer aided learning $(\mathrm{CAL})$ packages.

CAL packages have been produced to help students develop a variety of clinical skills, including recent advances in teaching communication and decision making skills to U.K. undergraduate pharmacists (Chapman \& Bracegirdle, 2010). While CAL has been successful in many ways, this learning style does not suit all, and the immediacy and realism of physical context is absent (Harasim, 1989; Moore, 1992). Some propose that teaching pharmacotherapeutics in a physical simulation environment is beneficial to learners in terms of interest levels and knowledge retention compared to other teaching methods (Seybert et al., 2006).

Simulation manikins do have limitations - typically the available drugs supplied with the simulator do not represent an exhaustive list. With the SimMan ${ }^{\mathbb{B}} 3 \mathrm{G}$, some are non-U.K. medicines, and so they either cannot be used or must be rebadged as U.K. equivalents. The software supporting SimMan ${ }^{\circledR} 3 \mathrm{G}$ provides a multinational consumer market, and therefore some doses used are not the same as those used in current treatment recommendations in the U.K.; doses must be modified to make the simulations relevant for U.K. students.

A recent extensive review into the features of effective simulation-based teaching and learning listed 'simulator validity' as one of the ten key features of quality (Issenberg et al., 2005). Validity in this context means simulation fidelity or realism. This feature was described beneficial as it allows learners to better "increase their visiospatial perceptual skills and to sharpen their responses to critical incidents" (Issenberg et al., 2005). In this context, the term fidelity can relate to the accuracy of physical representation of the simulator (physical fidelity), the extent to which the context represents real-life (environmental fidelity) and the effectiveness of the simulation in suspending disbelief in the learner (psychological fidelity) (Issenburg \& Scalese 2008; Rehman et al., 1995).

The use of a simulation manikin allows a more realistic teaching simulation for a number of reasons. It allows integration of multiple aspects of a clinical scenario; communication, physical interaction, immediate and dynamic pathophysiology and drug administration with appropriate responses. If the manikin is then placed within a convincing physical environment that includes the amenities of a real clinical setting, the level of fidelity is such that learners can experience a highly immersive simulation, anticipated to provide a superior teaching and learning experience compared to alternative methods.

Despite the high level of immersive fidelity that a manikinbased simulation can confer, the artefacts of simulation can detract from the experience. As well as problems mentioned above, oral administration of medicines cannot be carried out physically with the SimMan ${ }^{\circledR} 3 \mathrm{G}$, and must be role-played.

The teaching of clinical skills to pharmacists has become increasingly important; recently the General Pharmaceutical Council has included specific skills in its May 2011 document detailing standards for education and training. These skills are key to the development of a number of clinical roles, including prescribing pharmacists in all sectors, and consultative activities performed by community pharmacists as part of the public health role within the community pharmacy contractual framework. Providing pharmacy students access to real patients for teaching can be challenging, at least partly because there is competition for this resource from other health-discipline students. Simulation -based teaching of clinical skills therefore represents a realistic teaching solution.

While experience in the use of simulation manikins in undergraduate and postgraduate pharmacy programmes is increasing, it remains relatively rare, especially in the U.K. At present there are few published examples of experiences of using simulation manikins in undergraduate pharmacy courses in the U.K. mainland. Recently Reape et al., described their investigation comparing HPSs to traditional methods to teach aspects of critical care (2011).

\section{Where we are at the University of Bath}

In 2009, the department of Pharmacy and Pharmacology at the University of Bath acquired a SimMan ${ }^{\circledR} 3 \mathrm{G}$ manikin. An elective fourth-year unit was developed to use simulation scenarios to develop a range of clinical skills, including limited physical examination, communication and consultation, team-working and clinical decision-making/ problem-solving. SimMan ${ }^{\mathbb{B}} 3 \mathrm{G}$ is well designed for teaching medical and nursing students, with many acute medical scenarios tailored to the purpose. This model may fit pharmacy students less well. As healthcare professionals, even in prescribing roles, pharmacists are typically less 
involved in acute medicine, but tend to work in settings where clinical decision-making is less critically urgent. While this does not mean that the $\operatorname{SimMan}^{\circledR} 3 \mathrm{G}$ acute medical scenarios are inappropriate for the U.K. MPharm, it was noted that care must be taken in the design and execution of teaching material, and that the content be adapted for our students, in order to create an effective and appropriate learning experience.

\section{Aims}

The aim of this study was to investigate the use of a simulation manikin in the teaching of clinical skills to fourth year undergraduate MPharm students, to answer the following research questions:

1. Is simulation-scenario teaching an acceptable teaching and learning method for undergraduate pharmacists?

2. Is simulation-scenario teaching effective in increasing undergraduate pharmacist confidence in key clinical skills?

3. Is simulation-scenario teaching effective in improving undergraduate pharmacist self-perceived competence in key clinical skills?

\section{Methods}

\section{Unit design: Practicalities and organisation}

This study was carried out on the second cohort of students completing this programme. The unit ran over eight teaching weeks, six of which included a simulation scenario. Each simulation scenario week required students to complete a half hour real-time scenario in which they acted as a team in order to complete a consultation involving various clinical activities. Each simulation scenario was based on a clinical topic that had been covered previously in the undergraduate programme. This was intended to allow students to develop clinical skills while also consolidating and applying preexisting knowledge; consistent with Harden and Stampers' model of a spiral curriculum (1999). A diagrammatic explanation of the weekly teaching structure can be found in Figure 1.

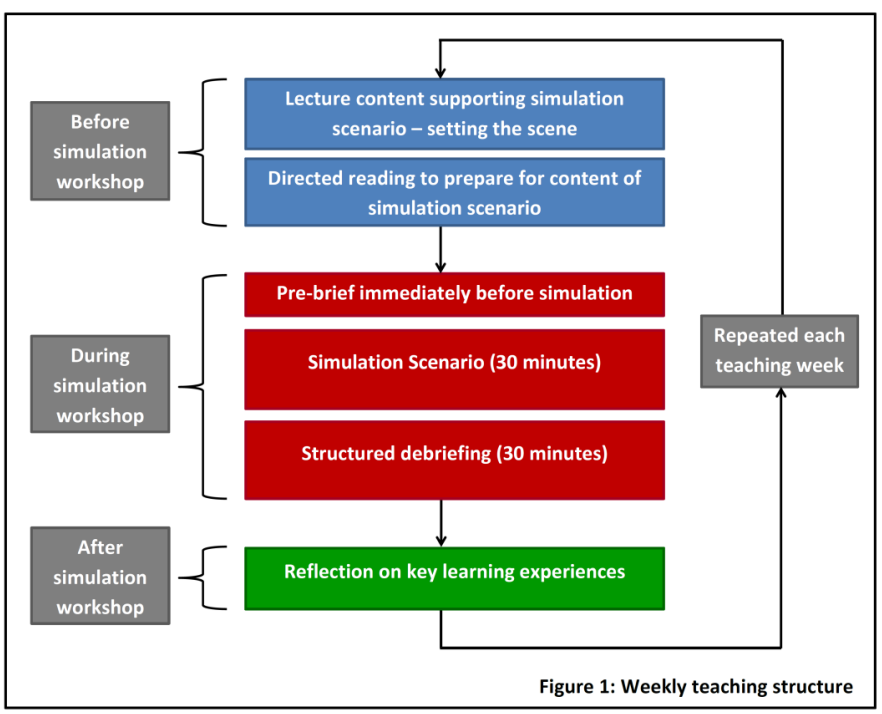

The cohort of 46 students was divided into groups of five to six for the simulation-scenarios. Each group experienced an hour of simulation-based teaching each week; the first 30 minutes as the simulation-based scenario, with the remainder as a structured debriefing. Student groups stayed the same throughout serial weeks. This was intended to allow a dynamic to develop within each group over time, after various well established theories (Tuckman, 1965; Tuckman \& Jensen, 1977). A member of academic staff was present in the simulation suite for each session as an observerfacilitator. This tutor then facilitated the following structured debriefing session.

\section{Simulation scenarios}

Three main types of simulation scenario design were used:

- Static physiology scenario: The patient does not undergo dynamic physiological changes, but communicates. These scenarios were intended to allow students to use and develop communication, physical examination and clinical decision making skills in a less acutely urgent setting.

- Dynamic physiology scenario: Scenarios were included which were more acute and rapidly progressive. The patient is non-communicative, and students were required to prioritise and manage an urgent situation. This was intended to focus the students on clinical decision-making within a more pressurised situation.

- Reactive scenarios: A communicative patient physiologically reacts rapidly and appropriately (with simulated anaphylaxis) in response to an inappropriately administered drug. This was designed as a highly complex clinical decision making process, included near the end of the unit.

The unit was designed with specific inclusion of aspects of simulation based learning that have been identified as being quality features, after the publications of Issenburg et al., (2005) and Ericsson (2004). These include:

- Incrementally increasing difficulty levels.

- The opportunity for repetitive practice of new and developing skills, supporting this through leading the students to use newly learned skills in serial weeks.

- The establishment of a highly 'controlled environment'; ensuring that learners and facilitators are not distracted during the process of scenario and debrief, and are able to make best advantage of learning opportunities.

The level of fidelity or realism that is encountered in a simulation has also been identified as being likely to affect the quality of learning experience. Experiences from other U.K. centres using simulations in teaching have reported that setting ground rules; a 'fiction contract' highlighting to students the elements of the simulation that have realism limitations, is likely to increase student emotional and intellectual engagement and immersion. This was therefore built into the introduction week and realism limitations were highlighted in each scenario pre-brief. 


\section{The debrief}

The use of structured, effective feedback within a debrief session as part of a simulated scenario has been identified as crucially important in simulation-based teaching (Issenburg et al., 2005). Debrief is based on much of the common theory that exists on feedback, but with some elements tailored to simulation-based learning (Ramprasad, 1983; Kluger \& DeNisi, 1996; Black \& Wiliam, 1998; Rudolph et al., 2006). A useful tool available to guide the effective use of debriefing in simulated scenario teaching is the Harvard DASH (Debriefing Assessment for Simulation in Healthcare) tool (Simon et al., 2009). This describes six key elements of debriefing:

\section{Establishes an engaging learning environment}

2. Maintains an engaging learning environment

3. Structures debriefing in an organised way

4. Provokes engaging discussions

5. Identifies and explores performance gaps

6. Helps trainees achieve or sustain good future performance

In order to achieve effective debrief and feedback, debrief sessions were dedicated half of the total workshop time available. Facilitators reviewed and applied the key elements of debrief described within the DASH tool.

The debrief sessions were designed with reflective practice at their centre. The intention was to use recognised debriefing strategies in order to facilitate students' identification of key learning points, future learning needs and application of learning in future practice. A modified 'Gibbs' cycle' tool was given to students at the start of the debrief and they were prompted to record immediate ideas from the simulation that they could then use guide reflection after the session (modified from Gibbs, 1988).

\section{Student questionnaires and data collection}

Pre- and post-unit student questionnaires were designed to gather data. The first questionnaire was completed by students after the introductory lecture on unit practicalities, but before students had experienced any simulations. Postunit questionnaires were given to students to complete in the final week (after the last simulation-scenario).

All questions were based on 5-point Likert scales. Some questions were repeated before and after the unit to allow comparison, and others were included only in the post-unit version. Some questions were adapted from investigators who have completed similar work on student acceptability in order to allow comparison (Seybert et al., 2006).

\section{Pre- and post-unit questions}

Questions 1 and 2 asked the students to rate how strongly they agreed with statements that they are CONFIDENT and COMPETENT in each of seven key clinical skills for the unit. Questions 3 to 9 asked the students to rate how strongly they agreed with a series of statements relating to the processes and outcomes of simulation-scenario learning, (using the same Likert scale) both pre- and post-unit. This was designed to determine whether experiencing simulation-scenario teaching changed their perceptions of this teaching method. It also further surveyed perceptions of the effects of simulationscenario learning on clinical skills improvement. Additional questions were included in the post-unit evaluation. These covered points of interest relating to intended learning outcomes, unit design and execution, and student experience. The results were analysed to determine whether changes in student responses before and after the unit were significantly different. The Wilcoxon Signed Rank test was used with a $p$ value $<0.05$ considered significant. $Z$ values were used to determine effect size (r).

\section{Results}

Of the 46 students participating in the unit, pre- and postquestionnaires were returned by 35 (76\%). As shown in Table I, there was a statistically significant improvement in student reported confidence and self-rated competence for all clinical skills ( $p$ value 0.004 or less for all results) with a medium or large effect size for all. In terms of the usefulness of simulation scenario learning (Table II), students agreed that their communication skills with patients would be increased through simulation-scenario learning. This agreement did not change between pre- and post- results, with the median response remaining 5 (strongly agree) and the mean increasing slightly. They also agreed that simulation-scenarios would be more beneficial for improving team-working skills than other methods of workshop-style learning. The median response changed from 4 (agree) to 5 (strongly agree) (Table II); this difference was non-significant. Students disagreed with the statement that this style of learning would be unlikely to improve the service for patients, and this disagreement increased slightly between pre- and post- results, but not significantly, with the median response changing from 2 (disagree) to 1 (strongly disagree).

Other findings suggested that as a learning environment, simulation-scenarios were both safe for the learner and effective, and this perception increased significantly in the post-unit results with an increase in median from 4 (agree) to 5 (strongly agree) $(p=0.000, \mathrm{r}=0.45$ and $0.002, \mathrm{r}=0.36$ respectively). Students disagreed with the statement that they would prefer to learn without simulation-scenarios; this did not change significantly between pre- and post- results ( $p$ value $=0.641$ ), with a median response of 1 (strongly disagree) before and after. Students enjoyed the opportunity to learn in simulation-scenarios with student agreement significantly increasing between pre- and post- results ( $p$ value $=0.002, r=0.34)$ and the median response changing from 4 (agree) to 5 (strongly agree). Finally, pre-unit findings indicated that students disagreed that simulation-scenarios were stress-free (median 2), this perception changed between pre- and post- results with an increase in median to 3 (neither agree nor disagree). This difference was statistically significant $(p$ value $=0.001, \mathrm{r}=0.39$ ) .

With regard to intended learning outcomes, the results in Table III show that students largely agreed or strongly agreed (median response 4 or 5) that the unit allowed them to apply pre-existing knowledge, develop their problem-solving skills, made them more confident and competent practitioners as they prepare to move into their first year in practice as preregistration pharmacists, and work within and lead teams. In 
Table I: Student self rating of confidence and competence relating to key clinical skills

\begin{tabular}{|c|c|c|c|c|c|c|c|c|c|c|}
\hline & $\begin{array}{l}\text { PRE: } \\
\text { Mean }\end{array}$ & $\begin{array}{l}\text { PRE: } \\
\text { Median }\end{array}$ & $\begin{array}{l}\text { POST: } \\
\text { Mean }\end{array}$ & $\begin{array}{l}\text { POST: } \\
\text { Median }\end{array}$ & $\begin{array}{c}\text { Wilcoxon } \\
\text { Signed Rank } \\
p \text { value } \\
\text { (effect size,r) }\end{array}$ & $\begin{array}{l}\text { PRE: } \\
\text { Mean }\end{array}$ & $\begin{array}{l}\text { PRE: } \\
\text { Median }\end{array}$ & $\begin{array}{l}\text { POST: } \\
\text { Mean }\end{array}$ & $\begin{array}{l}\text { POST: } \\
\text { Median }\end{array}$ & $\begin{array}{c}\text { Wilcoxon } \\
\text { Signed Rank } \\
p \text { value } \\
\text { (effect size,r) }\end{array}$ \\
\hline & \multicolumn{5}{|c|}{ 1. I am CONFIDENT to: } & \multicolumn{5}{|c|}{ 2. I am COMPETENT to: } \\
\hline $\begin{array}{l}\text { Perform physical examinations, (e.g. } \\
\text { taking a patient's pulse, taking a blood } \\
\text { pressure) }\end{array}$ & 1.97 & 2 & 4.03 & 4 & $0.000(\mathrm{r}=0.59)$ & 1.74 & 1 & 3.74 & 4 & $0.000(\mathrm{r}=0.59)$ \\
\hline Communicate with patients & 3.83 & 4 & 4.63 & 5 & $0.000(\mathrm{r}=0.52)$ & 3.71 & 4 & 4.57 & 5 & $0.000(\mathrm{r}=0.47)$ \\
\hline $\begin{array}{l}\text { Use a decision support algorithm in } \\
\text { practice }\end{array}$ & 2.66 & 3 & 4.51 & 5 & $0.000(\mathrm{r}=0.58)$ & 2.80 & 3 & 4.40 & 4 & $0.000(\mathrm{r}=0.55)$ \\
\hline Lead a consultation with a patient & 2.91 & 3 & 4.57 & 5 & $0.000(\mathrm{r}=0.60)$ & 2.91 & 3 & 4.46 & 4 & $0.000(\mathrm{r}=0.55)$ \\
\hline Work effectively in a team & 4.06 & 4 & 4.63 & 5 & $0.000(\mathrm{r}=0.49)$ & 4.09 & 4 & 4.63 & 5 & $0.000(\mathrm{r}=0.41)$ \\
\hline Act as a leader in a team & 3.60 & 4 & 4.11 & 4 & $0.003(\mathrm{r}=0.35)$ & 3.49 & 4 & 4.11 & 4 & $0.004(\mathrm{r}=0.35)$ \\
\hline $\begin{array}{l}\text { Problem solve and make decisions in } \\
\text { a clinical setting }\end{array}$ & 2.97 & 3 & 4.17 & 4 & $0.000(\mathrm{r}=0.55)$ & 3.00 & 3 & 4.14 & 4 & $0.000(\mathrm{r}=0.51)$ \\
\hline
\end{tabular}

Responses based on a Likert scale: 1 = Strongly Disagree, 2 = Disagree, 3 = Neither Agree nor Disagree, $4=$ Agree, $5=$ Strongly Agree

Table II: Student attitudes relating to simulated scenario learning (process and outcomes)

\begin{tabular}{|c|c|c|c|c|c|}
\hline & $\begin{array}{l}\text { PRE: } \\
\text { Mean }\end{array}$ & $\begin{array}{l}\text { PRE: } \\
\text { Median }\end{array}$ & $\begin{array}{l}\text { POST: } \\
\text { Mean }\end{array}$ & $\begin{array}{l}\text { POST: } \\
\text { Median }\end{array}$ & $\begin{array}{l}\text { Wilcoxon Signed Rank } \\
p \text { value (effect size,r) }\end{array}$ \\
\hline \multicolumn{6}{|l|}{ As a learning environment, I think simulated scenarios are: } \\
\hline ....Safe for me as a learner & 4.11 & 4 & 4.83 & 5 & $0.000(\mathrm{r}=0.45)$ \\
\hline ...Effective & 4.14 & 4 & 4.69 & 5 & $0.002(\mathrm{r}=0.36)$ \\
\hline ....Stress free & 2.03 & 2 & 2.77 & 3 & $0.001(\mathrm{r}=0.39)$ \\
\hline $\begin{array}{l}\text { My skills in communicating with patients may be improved through learning in } \\
\text { simulated scenarios. }\end{array}$ & 4.68 & 5 & 4.77 & 5 & $0.405(\mathrm{r}=0.01)$ \\
\hline I would prefer to learn without the use of simulated scenarios & 1.60 & 1 & 1.74 & 1 & $0.641(\mathrm{r}=0.06)$ \\
\hline $\begin{array}{l}\text { Learning in simulated scenarios may be more beneficial to improving my } \\
\text { teamwork skills than learning only with traditional practical classes or } \\
\text { workshops. }\end{array}$ & 4.34 & 4 & 4.57 & 5 & $0.120(\mathrm{r}=0.185)$ \\
\hline I enjoy the opportunity to learn in simulated scenarios. & 4.00 & 4 & 4.63 & 5 & $0.002(r=0.34)$ \\
\hline Learning in simulated scenarios is not likely to improve the service for patients & 1.54 & 2 & 1.49 & 1 & $0.433(\mathrm{r}=0.09)$ \\
\hline
\end{tabular}

terms of unit design and execution, Table IV shows that students agreed with statements relating to the effectiveness of the debrief sessions. Finally, in terms of student experience, the results in Table $\mathrm{V}$ demonstrate high levels of student satisfaction with simulation-scenarios as a teaching and learning tool. The majority of students agreed (median response 5) that this style of teaching provides a learning experience that cannot be achieved through other methods.

\section{Discussion}

Our findings support that the use of a simulation manikin to teach clinical skills was highly successful in increasing both student confidence and self-reported competence, and also represents a highly acceptable teaching method for undergraduate pharmacy students. These findings should, however, be considered in the context of some limitations.

Firstly, we did not and do not have methods in place to compare the effectiveness or acceptability of this teaching method to alternative methods. This would have provided a more comprehensive proof of outcomes. A potential avenue
Table III: Indicators relating to ILOs

\begin{tabular}{|l|c|c|}
\hline Statement & Mean & Median \\
\hline $\begin{array}{l}\text { The simulated scenarios allowed me to use } \\
\text { knowledge that I have learned in the degree course }\end{array}$ & 4.63 & 5 \\
\hline $\begin{array}{l}\text { This experience has helped to develop my ability } \\
\text { to solve problems }\end{array}$ & 4.40 & 4 \\
\hline $\begin{array}{l}\text { Participating in this unit has made me more } \\
\text { confident in my preparation for practice as a } \\
\text { pharmacist }\end{array}$ & 4.57 & 5 \\
\hline $\begin{array}{l}\text { Participating in this unit has made me more } \\
\text { competent in my future practice as a pharmacist }\end{array}$ & 4.40 & 4 \\
\hline $\begin{array}{l}\text { This unit has been effective in developing my } \\
\text { ability to lead a team }\end{array}$ & 4.17 & 4 \\
\hline $\begin{array}{l}\text { This unit has been effective in developing my } \\
\text { ability to work effectively as part of a team }\end{array}$ & 4.54 & 5 \\
\hline $\begin{array}{l}\text { Responses based on a Likert scale: 1 = Strongly Disagree, 2 = Disagree, } \\
3=\text { Neither Agree nor Disagree, 4 = Agree, 5 = Strongly Agree }\end{array}$ \\
\hline
\end{tabular}


Table IV: Indicators relating to unit design and execution

\begin{tabular}{|l|c|c|}
\hline Statement & Mean & Median \\
\hline The de-brief sessions after the scenarios were: & & \\
\hline $\begin{array}{l}\text {...Effective for reviewing my learning in the } \\
\text { scenario }\end{array}$ & 4.51 & 5 \\
\hline $\begin{array}{l}\text {...Effective for identifying my on-going learning } \\
\text { needs }\end{array}$ & 4.43 & 5 \\
\hline ...A safe setting to discuss my concerns and ideas & 4.60 & 5 \\
\hline $\begin{array}{l}\text {..Worrying as they might have exposed my } \\
\text { weaknesses }\end{array}$ & 2.00 & 2 \\
\hline $\begin{array}{l}\text { The facilitator was helpful in my learning } \\
\text { experience }\end{array}$ & 4.83 & 5 \\
\hline $\begin{array}{l}\text { The learning outcomes for this unit were clearly } \\
\text { defined (I knew what I was supposed to be } \\
\text { learning) }\end{array}$ & 4.03 & 4 \\
\hline $\begin{array}{l}\text { Responses based on a Likert scale: } 1=\text { Strongly Disagree, } 2= \\
\text { Disagree, } 3=\text { Neither Agree nor Disagree, } 4=\text { Agree, } 5=\text { Strongly } \\
\text { Agree }\end{array}$ & \\
\hline
\end{tabular}

Table V: Indicators relating to student experience

\begin{tabular}{|l|c|c|}
\hline Statement & Mean & Median \\
\hline I have enjoyed these simulated scenarios & 4.60 & 5 \\
\hline $\begin{array}{l}\text { Simulated scenarios provide a learning experience } \\
\text { that cannot be achieved in other ways (e.g. } \\
\text { through pure role play or OSCEs) }\end{array}$ & 4.63 & 5 \\
\hline $\begin{array}{l}\text { These simulated scenarios should be further } \\
\text { incorporated into the undergraduate curriculum }\end{array}$ & 4.83 & 5 \\
\hline \multicolumn{2}{|c|}{$\begin{array}{l}\text { Responses based on a Likert scale: 1 = Strongly Disagree, 2 = } \\
\text { Disagree, 3 = Neither Agree nor Disagree, 4 = Agree, 5 = Strongly } \\
\text { Agree }\end{array}$} \\
\hline
\end{tabular}

of investigation for the future may be to compare the teaching of similar clinical skills using different methods. In addition, it is important to note that the sample size was small. The students that responded to the questionnaires may be those that were most satisfied with the unit, thereby skewing the results. Students were well aware that this unit was newly designed and running only for the second time, and they often gave vocal support and positive feedback. It is possible therefore that those students who completed both questionnaires were a biased sample. Students who liked the unit less well may have felt alienated by the vocal support expressed by others, and therefore did not feel empowered to participate in the questionnaire or express negative feelings. Furthermore, as this unit is optional, the cohort is selfselecting, which may in itself introduce bias.

Finally, arbitrary pre- and post-unit self-rating of competence may not be a valid method of measuring changing competence in students. Student self-rating of competence clearly does not equate to actual clinical skills competence; it must be appreciated that these results look at student selfreported perceived competence. It would be a more robust measure if we had been able to measure student competence in the clinical skills before and after the unit using validated assessment tools. However, even given the acknowledgement of these caveats, it is reasonable to make some conclusions based on the results found.

The pre- and post-unit questions that related to student confidence and self-rated competence go a long way to demonstrate that this unit has been successful in improving student confidence and self-rated competence in the clinical skills. The use of measures which more objectively assess changes in students' clinical skills competence is a potential area for future research.

Given the lack of experience in using simulation manikin based teaching in undergraduate pharmacy courses, it was important for this study to determine how students perceived this style of learning, and how acceptable and they found simulation-based scenarios. The pre- and post-unit questions that related to the student experience told an interesting story. As well as demonstrating high levels of student acceptability and enjoyment, they also showed that student perceptions generally became more positive over the course of the unit. This suggests that while the students went into the unit with high expectations, their learning experiences were such that those expectations were met and perhaps even exceeded.

An interesting point is that many students disagreed that simulation scenarios were stress free, (although the median response changed to 3 'neither agree nor disagree' post-unit). While at the same time, students also reported that they enjoyed learning in simulated scenarios (35\% agreed and $63 \%$ strongly agreed), that they found the debriefing session a safe setting to discuss their concerns and ideas (23\% agreed $71 \%$ strongly agreed), and $80 \%$ disagreed that the debrief was worrying as it might expose their weaknesses. These figures might be explained by observations of the tutors that students appeared highly immersed in the scenarios, staying consistently in role and appearing to treat everything that happened seriously and as if it were real. It seems that the level of engagement and immersion that the students were experiencing was such that they found the simulation itself highly stressful; because they were emotionally and intellectually invested in what was happening. When the scenario ended, students were able to step out of character and enter into the debriefing in a very different state of mind; as they found the debrief safe. It was our experience that the students were able and happy to partake openly and fully in the debriefing, including discussing their perceived strengths and weaknesses.

This high level of student engagement in the scenarios hopefully goes some way to confirm the quality of simulation fidelity and validity that we managed to achieve, despite the anticipated simulation artefacts. In parallel to this, the student perceptions of the level of safety and effectiveness of the debriefing demonstrates that the evidence-based features we were consciously trying to integrate were successfully realised.

A final point for discussion is practicality; this method of learning is relatively resource intensive. Each group of students takes an hour to complete the simulation and subsequent debriefing. As the simulation and debriefing areas are separate, a staggered timetable means that two groups can be running at any given time. This achieved some time efficiency in terms of throughput, but required two members of teaching staff available at a time in order to realise this. While this reduced the overall teaching duration in a day, with a maximum group size of five to six students and the cohort divided into nine groups, this represented nine hours of contact teaching staff time each week that a clinical scenario was running, purely for the simulation scenarios. For these reasons, teaching staff and teaching space availability are the main limiters when facing the challenge of scaling this teaching method to larger cohorts. For schools of pharmacy considering pursuing a similar venture, another important aspect to consider is the acquisition and maintenance costs for 
a simulation manikin. At the time of writing these are around 50,000 - 70,000 GBP (depending on specification and servicing options) exclusive of VAT for a Laerdal SimMan ${ }^{\mathbb{B}} 3 \mathrm{G}$ similar to that used in this study. There is also the need for a suitably equipped simulation teaching room for the manikin to be located within, and an area for debriefing. The space requirements alone are likely to be problematic for many organisations.

\section{Conclusions}

The results from this research indicate that if it is properly tailored to MPharm students' learning needs, this use of a Human Patient Simulator is an effective method of teaching and learning clinical skills and increasing student confidence and competence. In addition, this method is perceived by students to be a highly acceptable method of learning. From the perspective of a tutor, the continuity of using the same tutor with a particular student group each week encouraged a positive learning experience for the students, successful use of the debrief session and enabled tutors to effectively assess student learning across the course of the module. As a bonus, for tutors and students, the use of an HPS made for an enjoyable learning environment. The main limitations of this learning approach are the relatively intensive resource requirements, both in terms of teaching contact time and acquisition and maintenance costs.

\section{References}

Black, P. \& Wiliam, D. (1998) Assessment and Classroom Learning. Assessment in Education: Principles. Policy \& Practice, 5 (1), 7-74.

Bokken, L., Rethans, J.J., van Heurn, L., Duvivier, R., Scherpbier, A. \& van der Vleuten, C. (2009) Students' Views on the Use of Real Patients and Simulated Patients in Undergraduate Medical Education. Academic Medicine, 84(7), 958-963.

Chapman, S.R. \& Bracegirdle, L. (2010) Programmable Patients: Simulation and consultation skills for virtual environment. Bio-algorithms and Med-Systems, 6(11), 111-115.

Ericsson, K.A (2004) Deliberate practice and the acquisition and maintenance of expert performance in medicine and related domains. Academic Medicine, 79(10, Suppl.), S70-S81.

General Pharmaceutical Council (2011) Future pharmacists: Standards for the initial education and training of pharmacists.

Gibbs, G. (1988) Learning by Doing: A guide to teaching and learning methods. Further Education Unit. Oxford Polytechnic: Oxford.

Harasim, L. (1989) Online education: a new domain. In Mindwave: communication, computers and distant education (eds. R. Mason \& A. Kaye), Oxford: Pergamon Press.

Harden, R.M., Stamper, N. (1999) What is a spiral curriculum? Medical Teacher, 21, 141-143.

Hatala, R., Issenberg, S.B., Kassen, B., Cole, G., Bacchus, C.M. \& Scalese, R.J. (2008) Assessing cardiac physical examination skills using simulation technology and real patients: a comparison study. Medical Education, 42(6), 628-636.
Issenberg, S.B., McGaghie, W.C., Hart, I.R., Mayer, J.W., Felner, J.M., Petrusa, E.R., Waugh, R.A., Brown, D.D., Safford, R.R., Gessner, I.H., Gordon, D.L. \& Ewy, G.A. (1999) Simulation technology for health care professional skills training and assessment. Journal of the American Medical Association , 282(9), 861-866.

Issenberg, S.B., McGaghie, W.C., Petrusa, E.R., Gordon, D.L. $\&$ Scalese, R.J. (2005) Features and uses of high-fidelity medical simulations that lead to effective learning: a BEME systematic review. Medical Teacher, 27(1), 10-28.

Issenberg, S.B. \& Scalese, R.J. (2008) Simulation in health care education. Perspectives in Biology and Medicine, 51(1), 31-46.

Kluger, A.N. \& DeNisi, A. (1996) The effects of feedback interventions on performance: a historical review, a metaanalysis, and a preliminary feedback intervention theory. Psychological Bulletin, 119, 254-284.

Lee, A. \& Berge, Z. (2011) Second Life in Healthcare Education: Virtual Environment's Potential to Improve Patient Safety. Knowledge Management and E-Learning: An International Journal, 3(1), 17-23.

Mangione, S. \& Nieman, L.Z. (1997) Cardiac auscultatory skills of internal medicine and family practice trainees: a comparison of diagnostic proficiency. Journal of the American Medical Association, 278, 717-22.

Moore, M.G. (1992) Distance education theory. American Journal of Distance Education, 5(3), 1-6.

Pugh, C.M. \& Youngblood, P. (2002) Development and Validation of Assessment Measures for a Newly Developed Physical Examination Simulator. Journal of the American Medical Informatics Association, 9(5), 448-460.

Ramaprasad, A. (1998) On the definition of feedback. Behavioral Science, 28, 4-13.

Reape, A., Lips-Nassif, C., Bailey, L., Ashwell, P. \& Brown, D. (2011) The use of human patient simulators for teaching UK pharmacy students about critical care. Pharmacy Education, 11 (1), 1-7.

Rehmann, A., Mitman, R. \& Reynolds, M. (1995) A handbook of flight simulation fidelity requirements for human factors research. Technical Report no. DOT/FAA/CT-TN96/46. Wright -Patterson AFB, OH: Crew Systems Ergonomics Information Analysis Center.

Rosen, K.R. (2008) The history of medical simulation. Journal of Critical Care, 23, 157-166.

Rudolph, J., Simon, R., Dufresne, R. \& Raemer, D. (2006) There's no such thing as nonjudgmental debriefing: a theory and method for debriefing with good judgement. Simulation in Healthcare, 1(1), 49-55.

Seybert, A.L., Laughlin, K.K., Benedict, N.J., Barton, C.M. \& Rea, R.S. (2006) Pharmacy Student Response to PatientSimulation Mannequins to Teach Performance-based Pharmacotherapeutics. American Journal of Pharmaceutical Education, 70(3), 48.

Simon, R., Raemer, D.B. \& Rudolph, J.W. (2009) Debriefing Assessment for Simulation in Healthcare - Rater Version. Cambridge, MA Center for Medical Simulation.

Tuckman, B.W. (1965) Developmental sequence in small groups. Psychological Bulletin, 63, 384-399. 